\title{
O Ensino da Epidemiologia
}

Neste começo de milênio, são evidentes as profundas mudanças políticas e sociais que vêm ocorrendo em todo o mundo, com repercussões significativas sobre o campo da saúde. Mudanças do perfil e distribuição das doenças e a intensificação das desigualdades sociais, por exemplo, vêm impondo desafios, com vistas a uma mais adequada conceitualização do processo saúde-doença, de definição de boas práticas de prevenção e controle, de diagnóstico e tratamento das doenças e de promoção da saúde. Nesse novo cenário destacam-se também os avanços da ciência que têm potencializado a inovação tecnológica e em especial a tecnologia da informação e da comunicação. Esses avanços transformaram de modo radical os modos convencionais de produção, acesso e disseminação do conhecimento. Na sociedade contemporânea, a cultura e o conhecimento ocupam lugar de destaque, contribuindo para a construção de identidades políticas, sociais e comportamentais.

Neste sentido, a construção de uma sociedade mais saudável e mais justa não pode ignorar o papel estratégico da educação. O ensino da Epidemiologia tem se defrontado com novos desafios, como o de produzir conhecimento em ritmo compatível com a transformação da sociedade, com o uso de recursos pedagógicos da era tecnológica, adequado às necessidades de um público em constante transformação cultural e comportamental e a uma sociedade que cobra eficiência, ética e transparência das suas instituições.

No Brasil, o último qüinqüênio trouxe ao campo da atenção à saúde, a consolidação do SUS, por meio da descentralização administrativa e financeira que fortaleceu a municipalização das ações, da gestão e do controle dos recursos públicos direcionados a este setor. De mais interesse para a formação em Epidemiologia, ressalta-se o aprimoramento e a ampliação do Sistema Nacional de Vigilância Epidemiológica (SNVE), que permitiu uma maior participação dos sistemas locais de saúde, notadamente com a Programação Pactuada Integrada (PPI), o Programa de Agentes Comunitários (PACS) e o Programa de Saúde da Família (PSF). A reestruturação e consolidação da Vigilância Sanitária no país, com a incorporação da vigilância ambiental, também causaram um aumento da demanda por qualificação dos serviços e dos recursos humanos para lidar com o risco sanitário, demandando, dentre outros saberes, a introdução da Epidemiologia na formação básica dos profissionais,. Todos esses direcionamentos levaram a um aumento da demanda por formação em Epidemiologia, com um novo olhar adequado às necessidades dos serviços de saúde. 
De um outro ponto de partida, a expansão do ensino superior e de pós-graduação no país, e também da pesquisa epidemiológica, causou um incremento na demanda por epidemiologistas qualificados. No entanto, a precariedade dos vínculos de emprego, como a ausência de carreira específica nas instituições públicas e a instabilidade dos contratos de trabalho, tem afetado egressos dos cursos de formação e contribuído, ocasionalmente, para a pouca motivação de alunos e professores envolvidos com essa tarefa.

Na discussão da formação de epidemiologistas, não se pode ignorar o contexto da reforma do ensino superior ora em curso, e das modificações em implementação pela CAPES/MEC com respeito à formação pós-graduada, a exemplo das redefinições que envolvem mestrados acadêmicos e profissionalizantes, e os cursos de especialização lato sensu. Essas novas proposições certamente irão causar impacto na construção e definição de um novo perfil de profissionais da saúde, e também dos epidemiologistas.

No campo da formação stricto sensu, ressalta-se o impacto positivo do sistema de avaliação da CAPES/MEC na qualidade dos cursos de pós-graduação, embora seja consenso que esse processo esteja a exigir redirecionamentos. Um exemplo é a pequena valorização da atividade docente e da produção acadêmica de propósito didático, nos indicadores de avaliação. Outro aspecto negligenciado é a qualidade da metodologia de ensino, comumente precária e conservadora, mas cuja avaliação ainda não é focalizada no atual sistema. E, em especial, o tipo de produção científica e os veículos de difusão que são mais valorizados no processo avaliativo. A avaliação dos mestrados profissionalizantes está por merecer indicadores mais condizentes com a especificidade dos seus objetivos de formação.

É nesse contexto que se colocam os desafios para a formação em Epidemiologia no país nos próximos anos.

\section{Formação em Epidemiologia para os serviços de saúde}

\subsection{Problemas identificados}

1.1.1 Crescente demanda por pessoal qualificado nos serviços como o PSF para o manejo, análise e interpretação de dados epidemiológicos, nas diversas regiões do país, em especial aquelas com menor concentração de recursos humanos qualificados;

1.1.2 Dificuldade em ampliar a produção de conhecimento epidemiológico ade- 
quado para uso por gestores municipais em nível individual e coletivo, o que requer o aprimoramento e aproximação dos materiais de instrução, seus conteúdos e abordagens, para as exigências impostas pela prática dos serviços de saúde;

1.1.3 Incipiente incorporação do conhecimento epidemiológico na formulação de políticas, particularmente na definição de prioridades, em especial as locais/municipais, e a conseqüente falta de coerência e consistência entre a implementação de ações de saúde e as necessidades e demandas da população;

1.1.4 Pouco uso das bases de dados e sistemas de informação disponíveis para análises de dados em nível regional ou municipal, e falta de formação dos profissionais de saúde para analisar esses dados de modo apropriado para as perguntas definidas pelos gestores;

\subsubsection{Precária infra-estrutura de equipamentos e recursos de informática} nas unidades de saúde, em especial dos municípios e regiões mais pobres do país;

1.1.6 Pouco estímulo e motivação dos profissionais dos serviços para um compromisso mais efetivo com a formação, resultante da instabilidade da inserção profissional, notadamente no nível municipal, o que expressa a falta de definição de carreira e plano de cargos e salários, que devem ser equivalentes e compatíveis com a continuação da qualificação e da complexidade das tarefas envolvidas;

1.1.7 A rapidez com que o conhecimento vem sendo produzido e se transformando em novas tecnologias impõe uma redefinição do modelo pedagógico implícito na formação de recursos humanos em Epidemiologia para os serviços. Este tem se pautado por uma perspectiva de terminalidade, expressa em diplomação ou titulação, seguida de cursos curtos, fragmentados, e pouco articulados com as necessidades concretas da população, o que pode resultar em baixo impacto e desperdício de recursos.

\subsection{Ações propostas}

1.2.1 Apoiar a formulação, discussão e difusão de novos modelos pedagógicos e de formação em Epidemiologia para os serviços de saúde, que enfatizem 
uma postura reflexiva, crítica, pró-ativa e criativa dos profissionais de saúde, voltada para os problemas reais da saúde coletiva no país, em uma perspectiva de educação permanente e continuada;

1.2.2 Apoiar a ampliação da oferta de oportunidades de formação coerentes com modelos pedagógicos e de formação definidos, que se sustentem em plano de carreira que aponte para um lugar definido do epidemiologista em todos os níveis da organização dos serviços de saúde;

1.2.3 Contribuir para que os novos modelos de formação se baseiem em uma estrutura modular, hierarquizada e contínua, que se sustente no mútuo reconhecimento de créditos, preservando-se as especificidades de conteúdo e complexidade, bem como a pertinência aos conteúdos curriculares mínimos exigidos em cada nível;

1.2.4 Estimular o desenvolvimento de indicadores de avaliação e desempenho, de alunos e programas de formação, coerentes com as especificidades do epidemiologista que atua em serviços de saúde;

1.2.5 Incentivar o uso e a avaliação de métodos de ensino à distância, que tem se mostrado uma ferramenta eficiente para a ampliação da oferta de oportunidades de formação, a custos aceitáveis, e com grande potencial para reduzir desigualdades regionais na distribuição de recursos humanos qualificados. Com a ampliação do uso dessa abordagem, poder-se-á alcançar profissionais em regiões de difícil acesso, permitindo assim os insumos necessários para a ampliação da cobertura e melhoria da qualidade dos serviços de saúde;

1.2.6 Apoiar a implantação da rede interinstitucional de formação em Epidemiologia para os serviços de saúde, centrada na vigilância em saúde, ora em implantação pela Secretaria de Vigilância em Saúde/MS;

1.2.7 Colaborar com o desenvolvimento de tecnologias e recursos instrucionais, como a produção de material didático, a exemplo de livros texto e em hipertexto, web-books, vídeos, animações, slides, dentre outras possibilidades, que empreguem linguagem e conteúdos que contemplem diferenças regionais, consistentes com os modelos pedagógicos e de formação definidos;

1.2.8 Considerando que a incorporação do conhecimento epidemiológico na ges- 
tão da saúde requer uma sensibilização e a capacitação de gestores, propõe-se o apoio à criação de meios de divulgação da Epidemiologia para esses profissionais. Nos cursos de capacitação deverá ser enfatizado o uso da Epidemiologia como ferramenta de gestão, o exercício da problematização de aspectos relevantes da saúde em suas regiões, e em especial do compartilhamento de experiências bem sucedidas do uso da Epidemiologia na gestão de serviços;

1.2.9 Incentivar a incorporação de habilidades de comunicação, e em especial a comunicação de riscos, como também a discussão de aspectos éticos envolvidos na prática da Epidemiologia na saúde pública e nos currículos dos programas de formação. Esta formação deverá contemplar a diversidade das exigências das diferentes audiências, como organizações e movimentos sociais, usuários, e demais atores sociais. Considera-se também relevante a inclusão de outros conteúdos como questões epidemiológicas de populações para as quais são ainda incipientes os estudos e a atuação do Estado, a exemplo das populações indígenas.

\section{Formação em Epidemiologia para a pesquisa e o ensino}

\subsection{Problemas identificados}

2.1.1 Imperfeições do sistema de avaliação da CAPES/MEC que precisam ser superadas, como a pouca valorização da atividade docente, da produção acadêmica de propósito didático, de livros e relatórios técnicos, ou de outros produtos de grande importância social e para os serviços de saúde. Avaliar algumas das exigências para a titulação de mestre e doutor, a exemplo das bancas públicas, que vêm sendo alvo de questionamentos quanto à sua eficiência, no que respeita a garantia da qualidade da formação.

2.1.2 Inadequação de métodos pedagógicos e de recursos instrucionais que não atendem ao perfil do novo aluno nem da tecnologia de informação e comunicação disponíveis;

2.1.3 Insuficiente articulação entre os programas de pós-graduação do país, que não promove a troca de experiências entre docentes e alunos de diferentes cursos;

2.1.4 Insuficiente discussão das demandas por cooperação estrangeira advindas 
de instituições de ensino de países africanos de língua portuguesa e da América Latina e Caribe;

2.1.5 Desigualdades geográficas na oferta de oportunidades de formação no país;

2.1.6 Falta de uma política definida de software, que priorize o desenvolvimento, aprimoramento e uso de software livre no ensino da Epidemiologia, em todos os níveis de formação;

2.1.7 Risco de dissociação entre a formação em Epidemiologia e a saúde pública, especialmente com os problemas decorrentes da maior complexidade do conhecimento, que exige extensão dos conteúdos curriculares, em tensão com a rigidez na duração dos programas de acordo com o formato recomendado pela CAPES;

2.1.8 Insuficiente discussão sobre o ensino da Epidemiologia na graduação, identificação dos seus problemas, desafios, e perspectivas para que venha a se constituir em importante instrumento de aprimoramento da formação dos profissionais de saúde.

\subsection{Ações propostas}

2.2.1 Realizar fóruns de discussão e ou incorporar à pauta dos Coordenadores de Pós-Graduação o aprimoramento da avaliação dos programas de pósgraduação em saúde pública e de Epidemiologia pela CAPES/MEC, que contemple as exigências para titulação e modos alternativos utilizados por alguns programas, como a pré-banca e prova de conhecimentos ao final do curso;

2.2.2 Incentivar a criação de um programa de apoio e bolsas de estudo para intercâmbio de alunos e professores entre os diversos programas de pósgraduação no país;

2.2.3 Reiterar junto a CAPES/MEC o incentivo e uma maior diversidade de apoio a programas de pós-graduação interinstitucionais;

2.2.4 Buscar a garantia da boa qualidade da formação em Epidemiologia levando em consideração a relação da Epidemiologia com a saúde coletiva; 
2.2.5 Apoiar a incorporação, nos currículos dos programas de pós-graduação, de questões éticas envolvidas na prática, seja nos serviços ou na pesquisa, que propicie uma maior reflexão sobre a regulamentação adotada no Brasil, e também sobre a atuação do pesquisador em sua relação com a sociedade;

2.2.6 Apoiar a realização de programas multilaterais de cooperação internacional com países vizinhos ou africanos, que garantam uma perspectiva bilateral e institucionalmente equilibrada. 